Document downloaded from:

http://hdl.handle.net/10251/68891

This paper must be cited as:

Moya, P.; Skaloud, P.; Chiva, S.; García-Breijo, F.; Reig-Arminana, J.; Vancurova, L.; Barreno, E. (2015). Molecular phylogeny and ultrastructure of the lichen microalga Asterochloris mediterranea sp. nov. from Mediterranean and Canary Islands ecosystems. International Journal of Systematic and Evolutionary Microbiology. 65(6):1838-1854. doi:10.1099/ijs.0.000185.

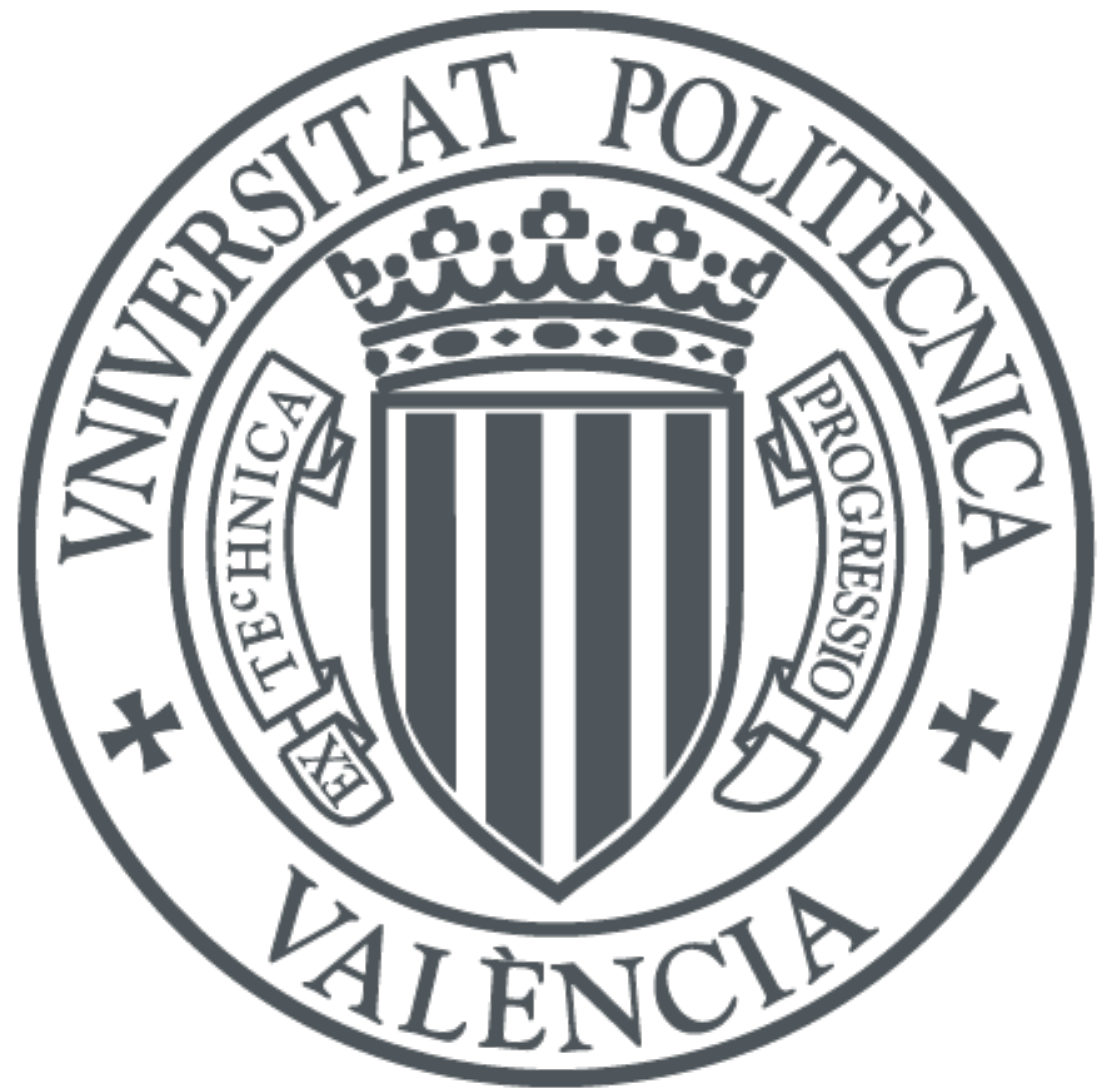

The final publication is available at

https://dx.doi.org/10.1099/ijs.0.000185

Copyright Microbiology Society

Additional Information 


\title{
Molecular phylogeny and ultrastructure of the lichen microalga Asterochloris mediterranea sp. nov. from Mediterranean and Canary Islands ecosystems
}

\author{
Patricia Moya, ${ }^{1}$ Pavel Škaloud, ${ }^{2}$ Salvador Chiva, ${ }^{1}$ \\ Francisco J. García-Breijo, 3,4 José Reig-Armiñana, ${ }^{1,3}$ Lucie Vančurová $^{2}$ \\ and Eva Barreno ${ }^{1}$ \\ ${ }^{1}$ Universitat de València, Dpto. Botánica, ICBIBE, Facultad Ciencias Biológicas, Dr Moliner 50, \\ 46100 Burjassot, Valencia, Spain \\ ${ }^{2}$ Charles University in Prague, Faculty of Sciences, Department of Botany, Benatska 2, \\ 12801 Praha 2, Czech Republic \\ ${ }^{3}$ Laboratorio de Anatomía Vegetal 'Julio Iranzo', Jardí Botànic de la Universitat de València, \\ Quart 80, 46008 Valencia, Spain \\ ${ }^{4}$ Dpto. Ecosistemas Agroforestales, Universidad Politécnica de Valencia. Camino de Vera, s/n., \\ 46022 Valencia, Spain
}

\begin{abstract}
The microalgae of the genus Asterochloris are the preferential phycobionts in Cladonia, Lepraria and Stereocaulon lichens. Recent studies have highlighted the hidden diversity of the genus, even though phycobionts hosting species of the genus Cladonia in Mediterranean and Canarian ecosystems have been poorly explored. Phylogenetic analyses were made by concatenation of the sequences obtained with a plastid - LSU rDNA - and two nuclear - internal transcribed spacer (ITS) rDNA and actin - molecular markers of the phycobionts living in several populations of the Cladonia convoluta-Cladonia foliacea complex, Cladonia rangiformis and Cladonia cervicornis s. str. widely distributed in these areas in a great variety of substrata and habitats. A new strongly supported clade was obtained in relation to the previously published Asterochloris phylogenies. Minimum genetic variation was detected between our haplotypes and other sequences available in the GenBank database. The correct identification of the fungal partners was corroborated by the ITS rDNA barcode. In this study we provide a detailed characterization comprising chloroplast morphology, and ultrastructural and phylogenetic analyses of a novel phycobiont species, here described as Asterochloris mediterranea sp. nov. Barreno, Chiva, Moya et Škaloud. A cryopreserved holotype specimen has been deposited in the Culture Collection of Algae of Charles University in Prague, Czech Republic (CAUP) as CAUP H 1015. We suggest the use of a combination of several nuclear and plastid molecular markers, as well as ultrastructural (transmission electron and confocal microscopy) techniques, both in culture and in the symbiotic state, to improve novel species delimitation of phycobionts in lichens.
\end{abstract}

Abbreviations: $\mathrm{Bl}$, Bayesian inference; $\mathrm{CBC}$, compensatory base change; CM, confocal microscopy; ITS, internal transcribed spacer; LM, light microscopy; ML, maximum-likelihood; SEM, scanning electron microscopy; TEM, transmission electron microscopy; wMP, weighted maximum-parsimony.

The GenBank/EMBL/DDBJ accession numbers for the ITS1-5.8S rRNA gene-ITS2-26S rRNA gene region of Asterochloris mediterranea are KP257366 to KP257398, those for the LSU rDNA gene are KP257300 to KP257332, and those for the actin gene are KP257333 to KP257365. The GenBank/EMBL/DDBJ accession numbers for the ITS1-5.8S rRNA gene-ITS2 region of the Cladonia convoluta-Cladonia foliacea complex, Cladonia rangiformis and Cladonia cervicornis s. str. are KP257399 to KP257424.

Two supplementary tables and one supplementary figure are available with the online Supplementary Material.

\section{INTRODUCTION}

Lichens exemplify the details of complex individuality since they are the outcome of cyclical obligate associations involving at least two very different organisms, a heterotrophic fungus (mycobiont) and a photoautotrophic (photobiont) cyanobacterium (cyanobiont) or/and a unicellular green alga (phycobiont, chlorobiont) (Barreno, 2013). Lichenization allows the partners to thrive in habitats that would otherwise be unavailable to either one on its own, and they are frequently successful in outperforming vascular plants, and even bryophytes, in terms of biodiversity as well as biomass. Lichens also host diverse and heretofore little explored communities of non-phototrophic lichenic bacteria 
(Aschenbrenner et al., 2014). Several patterns for mycobiontphycobiont interactions have been described, but the underlying mechanisms may differ considerably depending on the lichen species. Most of the studies on population structure have reported the presence of a single primary phycobiont species per thallus (Yahr et al., 2004; Muggia et al., 2008; Nelsen \& Gargas, 2008) or multiple phycobiont genotypes in a single thallus (Ohmura et al., 2006; Dal Grande et al., 2014; Muggia et al., 2014; Nyati et al., 2014). Additional complexity has been reported (Casano et al., 2011; del Campo et al., 2013; Molins et al., 2013) inside a single lichen thallus by the intrathalline coexistence of different algal species and/or genera.

Because of the obligate and intimate relationship between the photobionts and the mycobiont, it has been hypothesized that lichen symbioses undergoes long-term coevolution or concerted diversification (Ahmadjian, 1987; Rambold et al., 1998; del Campo et al., 2013). On the other hand, no overall co-speciation was evidenced between algal and fungal partners in the worldwide-distributed genus Cladonia (Piercey-Normore \& DePriest, 2001). This genus represents one of the largest genera of lichen-forming fungi with more than 400 described species (Ahti, 2000). Species of the genus Cladonia are often major contributors to overall biomass in diverse habitats and ecosystems (Lechowicz \& Adams, 1974; Munger et al., 2008). Moreover, Cladonia thalli are among the most complex of lichens, and the interpretation of phenotypic variation of their thalli has been controversial (Stenroos \& DePriest, 1998; Stenroos et al., 2002a, b; Grube \& Hawksworth, 2007). Several recent molecular studies have revealed a lack of correlation between morphological and molecular data, and many traditionally well-delimited species seem to be problematic (Myllys et al., 2003; Kotelko \& Piercey-Normore, 2010; Piercey-Normore et al., 2010; Pino-Bodas et al., 2012a, b, c; Steinová et al., 2013).

Cladonia represents a genus known for its prevailing specificity to Asterochloris algae (Piercey-Normore \& DePriest, 2001; Nelsen \& Gargas, 2006, 2008). This genus of microalga has been studied recently from the lichen fungi in the Cladoniineae (genera Cladonia, Lepraria, Stereocaulon) and in Diploschistes muscorum, a common parasite of species of the genus Cladonia (Škaloud \& Peksa, 2010; Škaloud et al., 2015). Phylogenetic analysis based on the concatenated set of internal transcribed spacer (ITS) rDNA and actin type I intron sequences revealed 20 well-resolved clades among Asterochloris phycobionts and particular clades were found to be associated with taxonomically different, but ecologically similar, lichens. Additional large hidden diversity in Asterochloris lineages was revealed in species of the genus Cladonia from India (Řídká et al., 2014).

Piercey-Normore \& DePriest (2001) showed that there are very few algal genotypes shared among variously related taxa of the family Cladoniaceae, implying that selectivity is not equal between lichen-forming fungi and algae. Contrasting findings suggested that different patterns of selectivity and specificity may occur in different lichen taxa
(Piercey-Normore, 2004; Yahr et al. 2004; Nelsen \& Gargas, 2008, 2009; Fernández-Mendoza et al., 2011; Magain \& Sérusiaux, 2014). Subsequent analyses (Peksa \& Škaloud, 2011) revealed that these Asterochloris phycobionts could exhibit clear preferences for environmental factors. These algal preferences may limit the ecological niches available to lichens and lead to the existence of specific lichen guilds. Likewise, recent physiological studies evidenced that dehydration rate and time of desiccation affect recovery in Asterochloris erici cultures; in addition proteomic and transcript analyses suggest that desiccation tolerance seems to be achieved by constitutive mechanisms in this alga (Gasulla et al., 2009, 2013).

Similar to other characteristics, the secondary structure of rRNA has also been used in evolutionary comparisons (Coleman et al., 1998; Lott et al., 1998; Hausner \& Wang, 2005). Patterns in the secondary structure of the ITS rRNA transcripts in Asterochloris and in other microalgae have been used as an additional attribute to delimit species boundaries (Beiggi \& Piercey-Normore, 2007; Škaloud \& Peksa, 2010; Škaloudová \& Škaloud, 2013). However, it was demonstrated that differences in the ITS rRNA secondary structures are often not diagnostic at the species level in green algae (Caisová et al., 2011; Škaloud \& Rindi, 2013).

This work was focused on four species of the genus Cladonia: Cladonia foliacea (Huds.) Willd., which is the most common and widely distributed species in the Mediterranean area, sharing its habitat with Cladonia convoluta (Lam.) Anders; Cladonia rangiformis Hoffm. and Cladonia cervicornis s. str. (Ach.) Flot. (Pino-Bodas et al., 2013a). All of these taxa grow preferentially in scrublands and forest clearings under prevailing dry bioclimates (Burgaz \& Ahti, 1992, 2009). Several studies (Burgaz \& Ahti, 1992, 2009; Litterski \& Ahti, 2004) have reported the controversy concerning how to morphologically, chemically and phylogenetically identify the differences between C. convoluta and C. foliacea; up to the present, it has been impossible to separate them into monophyletic groups, and the term C. convoluta-C. foliacea complex has been established (Pino-Bodas et al., 2010). The majority of molecular studies of species of the genus Cladonia have focused on mycobiont analyses, but the phycobiont has been mostly ignored and is poorly known.

In this study, we describe a novel phycobiont species, Asterochloris mediterranea sp. nov., discovered during our investigations into the phycobionts of Cladonia and other terricolous genera in the Mediterranean and Canary Islands ecosystems. Molecular and ultrastructural approaches led us to identify, and characterize in detail, this novel species both from thalli and isolated monoclonal cultures. Moreover, a key to the species of the genus Asterochloris has been drawn up.

\section{METHODS}

Taxa sampling. Specimens of C. foliacea (Huds.) Willd. and C. convoluta (Lam.) Anders (C. convoluta-C. foliacea complex), C. rangiformis Hoffm. 
and C. cervicornis s. str. (Ach.) Flot. were collected from different locations in the Iberian Peninsula and the Canary Islands (Fig. 1; Table $\mathrm{S} 1$ available in the online Supplementary Material). Samples were dried out in the shaded open air for 1 day and then stored at $-20{ }^{\circ} \mathrm{C}$ until needed.

Isolation and cultivation of phycobionts. The algal symbionts were isolated by the thallus fragmentation method (Ahmadjian, 1993; Peksa \& Škaloud, 2008) as follows: small fragments of lichen thalli were plated onto $2 \%$ agar slants of Bold's Basal Medium (BBM) as modified by Bischoff \& Bold (1963). The Petri dishes with thalli fragments were incubated at $18{ }^{\circ} \mathrm{C}$, under an illumination of 20 $30 \mathrm{mmol} \mathrm{m} \mathrm{m}^{-2} \mathrm{~s}^{-1}$ and a $16: 8 \mathrm{~h}$ light/dark cycle. If fungal contamination occurred during the cultivation, the contaminants were carefully removed or the thalli fragments were transferred to new plates. After 2-3 weeks, groups of dividing algal cells were observed associated with some of the fragments. To obtain unialgal cultures, small populations of phycobionts were transferred onto the fresh BBM agar slants and incubated accordingly.

Microscopic investigations. Light microscopy (LM), transmission electron microscopy (TEM) and scanning electron microscopy (SEM) techniques were performed for morphological analysis of 'in thallus' lichen phycobionts. Pieces of rehydrated C. convoluta-C. foliacea complex thalli from Fuentidueña de Tajo (Madrid) C6 and Bujaraloz (Zaragoza) $\mathrm{C} 16$ were used to examine the Asterochloris-type phycobionts inside the thalli. To analyse the morphology of chloroplasts in isolated phycobionts, confocal microscopy (CM) was used. TEM and SEM examinations were made at the SCSIE Service of the University of Valencia.

Light microscopy (LM). For LM analyses, 15-20 $\mu \mathrm{M}$ sections were cut from frozen samples with a sliding microtome (Leica SM 2000R). The sections were observed with an Olympus BX40 microscope equipped with an Olympus SC100-10.6 camera.

Transmission electron microscopy (TEM). For TEM, the cells were fixed in $2 \%$ Karnovsky fixative for $6 \mathrm{~h}$ at $4{ }^{\circ} \mathrm{C}$, and washed three times for 15 min with $0.01 \mathrm{M} \mathrm{PBS}, \mathrm{pH} 7.4$, and post-fixed with $2 \% \mathrm{OsO}_{4}$ in $0.01 \mathrm{M} \mathrm{PBS}, \mathrm{pH} 7.4$, for $2 \mathrm{~h}$ at room temperature. Thereafter, they were washed three times in $0.01 \mathrm{M} \mathrm{PBS}, \mathrm{pH} \mathrm{7.4,} \mathrm{for} 15 \mathrm{~min}$ and then dehydrated at room temperature in a graded series of ethanol, starting at $50 \%$ and increasing to $70 \%, 95 \%$ and $100 \%$ for no less than $20-30 \mathrm{~min}$ for each step (Casano et al., 2011; Molins et al., 2013). The fixed and dehydrated samples were embedded in Spurr's resin according to the manufacturer's instructions (Spurr, 1969). Sections (90 nm) were cut with a diamond knife (DiATOME Ultra $45^{\circ}$ ) using an ultramicrotome (LKB Bromma Nova Ultratome), mounted on copper grids of 100 mesh and post-stained using a SynapTek Grid Staining kit (Electron Microscopy Sciences; http://www.ems-diasum.com/microscopy/technical/ datasheet/71175.aspx). The sections were observed with a JEOL JEM$1010(80 \mathrm{kV})$ electron microscope, equipped with a MegaView III digital camera and AnalySIS image acquisition software.

Scanning electron microscopy (SEM). SEM was undertaken in order to observe the surface ultrasculpture of the squamules. Fractured

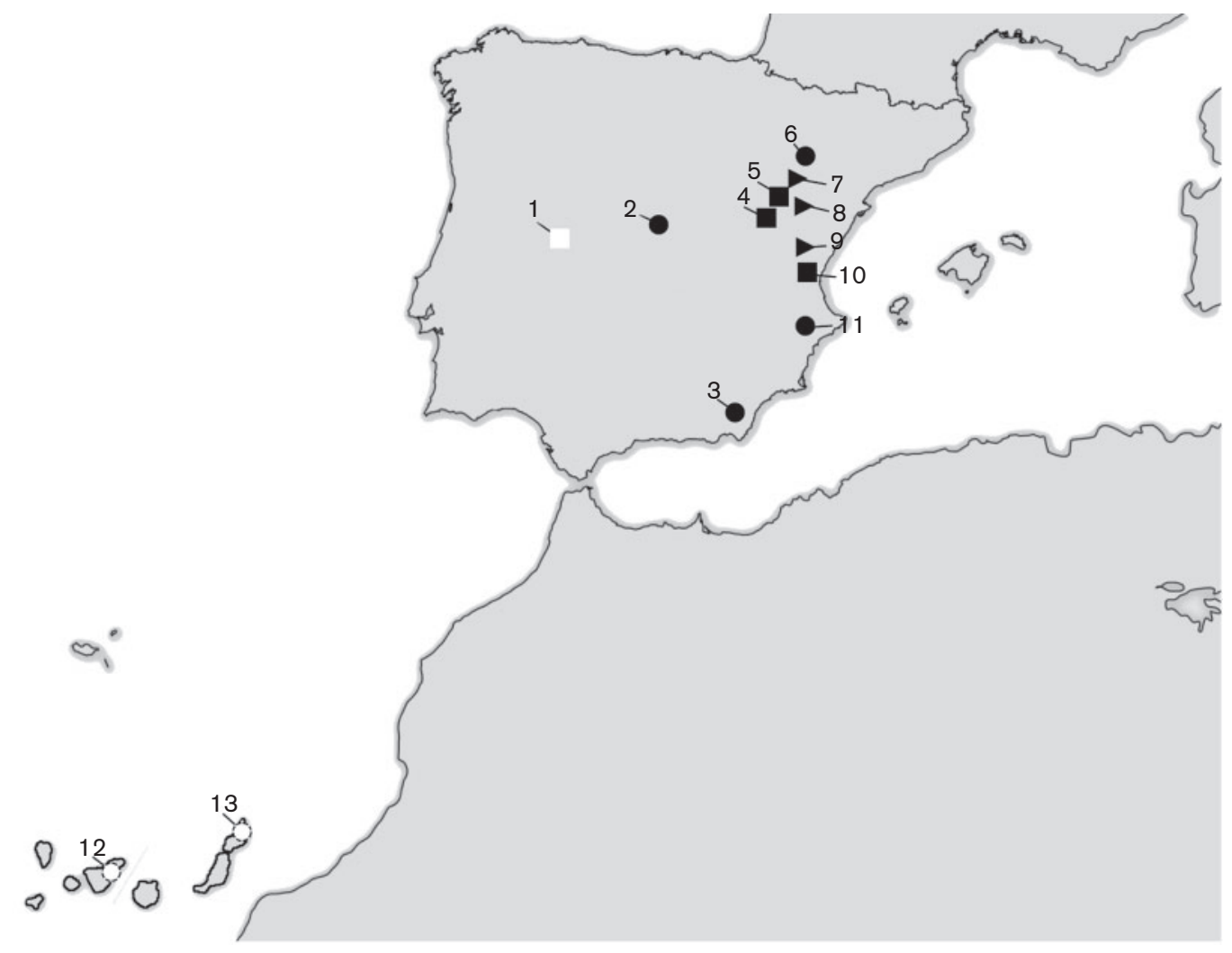

Fig. 1. Distribution of the Cladonia samples collected for this study in the Iberian Peninsula and the Canary Islands. Sites 1 to 13 and the various types of substrate are indicated by symbols: quartzites, siliceous (white square $\square$ ), limestones, calcareous (black square $\mathbf{0}$ ), sandstones, siliceous (black triangle $\longrightarrow$ ), Miocene gypsum (black circle $\mathbf{0}$ ) and volcanic (white discontinuous circle (). Details of the sampling sites are given in Table S1. 
thalli were attached to the holder, coated with palladium/gold and viewed with a Hitachi S-4800 field emission scanning electron microscope.

Confocal microscopy (CM). A Leica TCS SP2 laser scanning confocal microscope equipped with an argon-krypton laser was used. We applied a $488 \mathrm{~nm}$ excitation line and an AOBS filter-free system collecting emitted light between 498 and $700 \mathrm{~nm}$. The autofluorescence of chlorophyll was exploited for visualization of the chloroplast structure. A series of optical sections through chloroplasts was captured and used for threedimentional reconstruction of their morphology. The chloroplast reconstructions were produced by the ImageJ $1.34 \mathrm{p}$ program (Abràmoff et al., 2004), using the 'Volume viewer' plugin.

DNA isolation, amplification and sequencing. Individuals from localities 1 to 13 (Fig. 1) were analysed after washing performed following the protocol of Muggia et al. (2013). Samples were given an alphanumeric code from $\mathrm{C} 1$ to $\mathrm{C} 33$ as shown in Table 1. Total genomic DNA was isolated and purified using a Dneasy Plant Minikit (Qiagen) following the manufacturer's instructions.

Three algal loci were amplified from genomic DNA from each lichen thallus. As chloroplast genome marker, we studied a region of the LSU rRNA gene by using the algal-specific primers 23SU1 and 23SU2 (del Campo et al., 2010a). We also amplified two nuclear loci encoding the nrITS RNA, using the algal-specific primer nr-SSU-1780 (Piercey-Normore \& DePriest, 2001) and the universal primer ITS4 (White et al., 1990), and actin type 1, using the algal-specific primer pair ActinF2 Astero (Škaloud \& Peksa, 2010) and a-nu-act1-0818-3' (Nelsen \& Gargas, 2006). The primers used to amplify the nuclear ITS rRNA from the mycobiont were ITS1F (Gardes \& Bruns, 1993) and ITS4 (White et al., 1990).

Table 1. List of taxa included in this study, code ( $\mathrm{C} 1$ to $\mathrm{C} 33)$ used in phylogenetic analysis, and the GenBank accession numbers for the newly determined ITS rDNA, LSU rDNA and actin sequences, locality and type of substrate (see also Fig. 1 and Table S1)

\begin{tabular}{|c|c|c|c|c|c|c|}
\hline \multirow[t]{3}{*}{ Taxon } & \multirow[t]{3}{*}{ Code } & \multicolumn{4}{|c|}{ GenBank accession number } & \multirow{3}{*}{$\begin{array}{c}\text { Locality \& type of } \\
\text { substrate }\end{array}$} \\
\hline & & \multicolumn{3}{|c|}{ Phycobiont } & \multirow{2}{*}{$\begin{array}{l}\text { Mycobiont } \\
\text { ITS rDNA }\end{array}$} & \\
\hline & & ITS rDNA & LSU rDNA & Actin & & \\
\hline C. conv-fol complex & $\mathrm{C} 1$ & KP257366 & KP257300 & KP257333 & KP257399 & $2 \bullet$ \\
\hline C. conv-fol complex & $\mathrm{C} 2$ & KP257367 & KP257301 & KP257334 & KP257400 & $2 \bullet$ \\
\hline C. conv-fol complex & $\mathrm{C} 4$ & KP257369 & KP257303 & KP257336 & KP257427 & $2 \bullet$ \\
\hline C. conv-fol complex & $\mathrm{C} 5$ & KP257370 & KP257304 & KP257337 & KP257426 & 20 \\
\hline C. conv-fol complex & C6 & KP257371 & KP257305 & KP257338 & KP257428 & $2 \bullet$ \\
\hline C. conv-fol complex & $\mathrm{C} 7$ & KP257372 & KP257306 & KP257339 & KP257401 & $2 \bullet$ \\
\hline C. conv-fol complex & $\mathrm{C} 8$ & KP257373 & KP257307 & KP257340 & KP257402 & $2 \bullet$ \\
\hline C. conv-fol complex & C9 & KP257374 & KP257308 & KP257341 & KP257403 & $2 \bullet$ \\
\hline C. conv-fol complex & $\mathrm{C} 14$ & KP257379 & KP257313 & KP257346 & KP257408 & $3 \bullet$ \\
\hline C. conv-fol complex & $\mathrm{C} 15$ & KP257380 & KP257314 & KP257347 & KP257409 & $3 \bullet$ \\
\hline C. conv-fol complex & $\mathrm{C} 16$ & KP257381 & KP257315 & KP257348 & KP257410 & $6 \bullet$ \\
\hline C. conv-fol complex & $\mathrm{C} 17$ & KP257382 & KP257316 & KP257349 & KP257411 & $6 \bullet$ \\
\hline C. conv-fol complex & $\mathrm{C} 18$ & KP257383 & KP257317 & KP257350 & KP257412 & $6 \bullet$ \\
\hline C. conv-fol complex & $\mathrm{C} 19$ & KP257384 & KP257318 & KP257351 & KP257413 & $11 \bullet$ \\
\hline C. conv-fol complex & $\mathrm{C} 20$ & KP257385 & KP257319 & KP257352 & KP257414 & $1 \square$ \\
\hline C. conv-fol complex & $\mathrm{C} 21$ & KP257386 & KP257320 & KP257353 & KP257415 & $1 \square$ \\
\hline C. conv-fol complex & $\mathrm{C} 22$ & KP257387 & KP257321 & KP257354 & KP257416 & $1 \square$ \\
\hline C. conv-fol complex & $\mathrm{C} 23$ & KP257388 & KP257322 & KP257355 & KP257417 & $4 \square$ \\
\hline C. conv-fol complex & $\mathrm{C} 24$ & KP257389 & KP257323 & KP257356 & KP257418 & $5 \square$ \\
\hline C. cervicornis s. str. & $\mathrm{C} 32$ & KP257397 & KP257331 & KP257364 & KP257423 & $1 \square$ \\
\hline C. cervicornis s. str. & C33 & KP257398 & KP257332 & KP257365 & KP257424 & $1 \square$ \\
\hline
\end{tabular}

C. convoluta-C. foliacea complex are indicated as C. conv-fol complex. 
PCRs were performed in $50 \mu \mathrm{l}$ using EmeraldAmp GT PCR Master Mix (Takara). The only user-supplied reagents that need to be added are template DNA, specific primers and water, allowing for improved reproducibility while minimizing the potential for contamination. Negative controls, without a DNA template, were included in every round of PCR amplification to ensure against false-positive results caused by contaminants in the reagents. The PCR programme for amplifications comprised an initial denaturation at $94^{\circ}, 2$ min, and 30 cycles of $94{ }^{\circ} \mathrm{C}$ for $30 \mathrm{~s}, 56{ }^{\circ} \mathrm{C}$ for $45 \mathrm{~s}$ and $72{ }^{\circ} \mathrm{C}$ for $1 \mathrm{~min}$, followed by a final elongation at $72{ }^{\circ} \mathrm{C}$ for $5 \mathrm{~min}$. Amplifications were carried out on a 96-well SensoQuest labcycler (Progen Scientific). The PCR products were separated on $2 \%$ agarose gels and purified using Real Clean Spin (Durviz). The amplified PCR products were sequenced with an ABI 3100 Genetic analyser using the ABI BigDye Terminator Cycle Sequencing Ready Reaction kit (Applied Biosystems).

Sequence analyses. A multiple alignment of the newly determined fungal ITS rDNA (accession nos KP257399 to KP257424), algal ITS rDNA (KP257366 to KP257398), actin (KP257333 to KP257365) and LSU rDNA (KP257300 to KP257332) sequences and selected fungal ITS rDNA sequences described by Pino-Bodas et al. (2010) was built using MAFFT, version 6, applying the Q-INS-i strategy (Katoh et al., 2002). The alignment of actin sequences was improved by eliminating the ambiguously aligned regions using the program Gblocks v. $0.91 \mathrm{~b}$ (Castresana, 2000). The three loci were concatenated, yielding an alignment of 2036 characters. The final matrix contained 62 ITS rDNA, 62 actin and 34 LSU rDNA sequences. For each locus, the most appropriate substitution model was estimated using the Akaike information criterion (AIC) with PAUP/MrModeltest 1.0b (Nylander, 2004). This AIC-based model selection procedure selected the GTR $+\Gamma$ model for the mycobiont ITS rDNA, and the three following models for the phycobiont datasets: (1) GTR $+\mathrm{I}+\Gamma$ for ITS rDNA, (2) GTR $+\Gamma$ for the actin gene, and (3) HKY $+\mathrm{I}$ for LSU rDNA.

The phylogenetic trees were inferred by Bayesian inference (BI) using MrBayes version 3.2.1 (Ronquist et al., 2012), carried out on partitioned datasets using the different substitution models selected by PAUP/MrModeltest $1.0 \mathrm{~b}$. All parameters were unlinked among partitions. Two parallel Markov chain Monte Carlo (MCMC) runs were carried out for ten million generations, each with one cold and three heated chains. Trees and parameters were sampled every 100 generations. Convergence of the two cold chains was assessed during the run by calculating the average standard deviation of split frequencies (SDSF). The SDSF value between simultaneous runs was 0.0025 . Finally, the burn-in values were determined using the 'sump' command.

Bootstrap analyses were performed by maximum-likelihood (ML) and weighted maximum-parsimony (wMP) criteria using GARLI, version 2.01 (Zwickl, 2006) and PAUP*, version 4.0b10 (Swofford, 2002), respectively. ML analysis consisted of rapid heuristic searches (100 pseudo-replicates) using automatic termination (genthreshfortopoterm command set to 100000 ). The analysis was performed on partitioned datasets using the different substitution models. The wMP bootstrapping (1000 pseudo-replicates) was performed using heuristic searches with 100 random sequence addition replicates, tree bisection reconnection swapping, random addition of sequences, and gap characters treated as missing data. Character weights were assigned using the rescaled consistency index on a scale of 0 to 1000 . New weights were based on the mean fit values for each character over all trees in the memory.

Haplotype network. To show the genetic diversity within the newly characterized lineages, we reconstructed the haplotype networks on the basis of MP analyses of all available sequences, including those selected from the GenBank database (Table 2), using the Haplotype Viewer (G. Ewing, available at www.cibiv.at/ greg/haploviewer).

Phycobiont ITS2 secondary structure. The coding regions, required for the basal stems in ITS2 secondary structures, were delimited by comparison between our sequences and known sequences of Asterochloris (Beiggi \& Piercey-Normore, 2007). The stem-loop structures were folded using the ITS2DATABASE (Koetschan et al., 2010). If more than one fold was produced, the final fold was based on comparisons with those previously published for Asterochloris (Beiggi \& Piercey-Normore, 2007), maximizing the hydrogen bonding forming solid stems, and the largest negative $\Delta g$ value (free energy).

\section{RESULTS}

\section{Asterochloris mediterranea sp. nov. Barreno, Chiva, Moya et Škaloud (Figs 2, 3 and 4)}

Description. Mature vegetative cells spherical in shape, but oval, pyriform and kidney shapes are not uncommon, 8.28.5 to $12-16.3 \mu \mathrm{m}$ in diameter. Single central chloroplast

Table 2. GenBank fungal ITS rDNA sequences described by Pino-Bodas et al. (2010) included in the phylogenetic analysis and algal ITS rDNA (Pino-Bodas et al., direct submission; Piercey-Normore \& DePriest, 2001) included in the haplotype network analysis

\begin{tabular}{|c|c|c|c|c|c|}
\hline Mycobiont & Collection & Fungal ITS & Algal ITS & Locality & Substrate \\
\hline C. convoluta & MACB 90565 & FM205886.1b & FM205732 & Granada, Spain & Limestone $\mathbf{\square}$ \\
\hline C. convoluta & MACB 90565 & FM205886.1c & FM205730 & Granada, Spain & Limestone $\mathbf{\square}$ \\
\hline C. convoluta & MACB 91687 & FM211899 & FM205729 & Guadalajara, Spain & Sandstone \\
\hline C. foliacea & MACB 95599 & FM205914 & FM205728 & Trás-os-Montes, Portugal & Granite $\triangleright$ \\
\hline C. foliacea & MACB 90533 & FM205897 & FM205727 & Guadalajara, Spain & Granite $\triangleright$ \\
\hline C. foliacea & MACB 90574 & FM205895 & FM205725 & Tarragona, Spain & Granite $\triangleright$ \\
\hline C. foliacea & MACB 91639 & FM205899 & FM205724 & Ávila, Spain & Quartzite $\square$ \\
\hline C. convoluta & MACB 90440 & FM205901 & FM205723 & Barcelona, Spain & Limestone $\mathbf{\square}$ \\
\hline C. convoluta & МACB 90499 & FM205900 & FM205722 & Navarra, Spain & Limestone $\mathbf{\square}$ \\
\hline C. convoluta & MACB 90565 & FM205886.1 & FM205721 & Granada, Spain & Limestone $\mathbf{\square}$ \\
\hline C. foliacea & MACB 90503 & FM205898 & FM205720 & Alto Alentejo, Portugal & Quartzite $\square$ \\
\hline C. rangiformis & Frost-Olsen 5501 & - & AF345435 & Yugoslavia & - \\
\hline Cladonia fimbriata & Gustavsson \& Thollesson s.n. & - & AF345434 & Gothenburg, Sweden & - \\
\hline
\end{tabular}


with margins extended into finger-like, divided lobes. Central pyrenoid, spherical or irregularly elongated, of irregularis-type. One nucleus with nucleolus. Cell wall thin, $0.3-0.5 \mu \mathrm{m}$ wide, with flat local thickening and irregular secretory spaces. Asexual reproduction by $64-128$ spherical aplanospores.

Type locality. Phycobiont of C. convoluta-C. foliacea complex, collected on gypsum soils in Fuentidueña de Tajo (Madrid, Spain), $40^{\circ} 07^{\prime} 87^{\prime \prime} \mathrm{N} 03^{\circ} 09^{\prime} 12^{\prime \prime} \mathrm{W}$, altitude $571 \mathrm{~m}$, upper mesomediterranean low dry (leg. Barreno, Chiva, Molins \& Salvá 24 February 2012). The lichen specimen was deposited in herbarium PRC (no. 2939). Samples of the same population are in MA-Lich (no. 18201), VAL_Lich (no. 30278) and MAFLich (no. 19479).

Holotype. Cryopreserved cells of strain C6, deposited at the Culture Collection of Algae of the Charles University in Prague (CAUP), as item TYPE - H 1015.

Reference strains. CAUP H 1015 and E. Barreno's Lab in the Universitat de València (no. 131).

Molecular signatures. Hemi-CBCs in helix III (C-G: U-G; unique) and (G-G:C-G) of the ITS2 as compared with the ITS2 rRNA secondary transcripts of Asterochloris phycobiontica.

Etymology. Asterochloris mediterranea (me.di.ter.ra'ne.a.).

Etymology: L. fem. adj. mediterranea midland, inland and, in late Latin, used to refer to the Mediterranean Sea or bioclimatic types (Rivas-Martínez \& Rivas-Sáenz, 2009).

The specific epithet refers to the wide but not exclusive Mediterranean distribution and the relative abundance of several Cladonia mycobionts, which are up to now the most frequent hosts of this phycobiont.

Distribution. So far only known in the Iberian Peninsula, former Yugoslavia, Sweden and the Canary Islands.

Ecology. At the time of writing it has been found in symbiosis with $C$. convoluta-C. foliacea complex, $C$. rangiformis, Cladonia fimbriata and C. cervicornis s. str. lichen thalli growing in a wide variety of habitats, from lowlands to Mediterranean mountains, and on soils derived from very different types of rocks (gypsum, limestones, quartzites, granites, sandstones, volcanic).

\section{Morphological and ultrastructural characterization}

The squamules analysed in this study showed a strongly fissured and cracked surface (Fig. 2a, b), similar to the features previously noticed by Osyczka \& Rola (2013), who found a full range of surface roughness under SEM in different species of the genus Cladonia growing in non-arid or dry habitats.
In this study, LM, SEM and TEM were used to characterize the structure and ultrastructure of the cells of Asterochloris mediterranea sp. nov. found in C. convoluta-C. foliacea complex, C. rangiformis and C. cervicornis s. str. (Figs 2 and 3). The observations were made on samples C6 and C16, and no differences were found between them. The phycobionts were usually located in close contact with the hyphae in the phycobiont layer; the interactions between photobiont cells and fungal hyphae were the 'simple' type (Honegger, 1986), without invaginations or haustoria (Fig. $2 \mathrm{a}, \mathrm{b}, \mathrm{c})$. Mature vegetative cells were mostly spherical, but oval, pyriform and kidney shapes were also common, 8.28.5 to $12-16.3 \mu \mathrm{m}$ in diameter. The cell wall exhibited a variable thickness, ranging from 0.3 to $0.5 \mu \mathrm{m}$, with flat local thickening and irregular secretory spaces giving a characteristic appearance to the young and mature vegetative cells. Both in thallus and culture, the cells showed a large, axial and lobed chloroplast with margins extended into finger-like lobes in the periphery characteristic of the genus Asterochloris (Fig. 2c, d). The thylakoid membranes were grouped in stacks shaped by $4-5$ membranes, similar to the grana in vascular plants (Fig. 3b, c, e, f). A large central portion of the chloroplast was taken up by the pyrenoid (Figs 2e, f and 3a, c, d). Usually, there was only one pyrenoid per cell, although in some cases two could appear (Fig. 3d). This pyrenoid might be spherical or irregularly elongated (Fig. 3a, c), with a small number of thin, arched thylakoid tubules invaginating within the matrix. Numerous pyrenoglobuli $(80-100 \mathrm{~nm}$ in diameter) were connected with these tubules (Fig. 3b). This ultrastructure fits into the irregularis-type (Friedl, 1989). Spherical non-electron-dense vesicles appeared throughout the cytoplasm and were especially numerous at the periphery (Figs 2e, $\mathrm{f}$ and $3 \mathrm{a}$ ). Also, some small mitochondria were observed (Fig. 3e). Most of the cells presented numerous ribosomes in the cytoplasm (Fig. 3e, f) and showed a clear and apparent nucleus with nucleolus (Figs $2 \mathrm{f}$ and $3 \mathrm{~d}$ ). The plasmatic membrane showed invaginations in many areas connected with secretory vesicles (Fig. 3e). Secretory spaces were irregular in thickness and myelin-like bodies could be seen in some cases (Fig. 3e). Two types of myelin-like bodies were detected, the plasmalemmasomes in the secretory spaces (Fig. 3e) outlined by evagination of the plasmalemma as well as by fusion of vesicles, and lomasomes (Fig. S1) associated with the rough endoplasmic reticulum (Marchant \& Robards, 1968; Robards, 1968). Aplanospores by 64-128 in the sporocysts were spherical (Fig. 2d).

\section{Chloroplast morphology of isolated lichen phycobionts}

Once unialgal cultures were obtained as previously described, confocal reconstructions showed that the majority of the cell volume was occupied by the chloroplast (Fig. 4). In young cells, the chloroplast was central, axial, with simple lobes spreading towards the cell periphery (Fig. 4a). Mature vegetative cells could possess a similarly formed, shallowly lobed plastid with simple lobes. However, the lobes were 

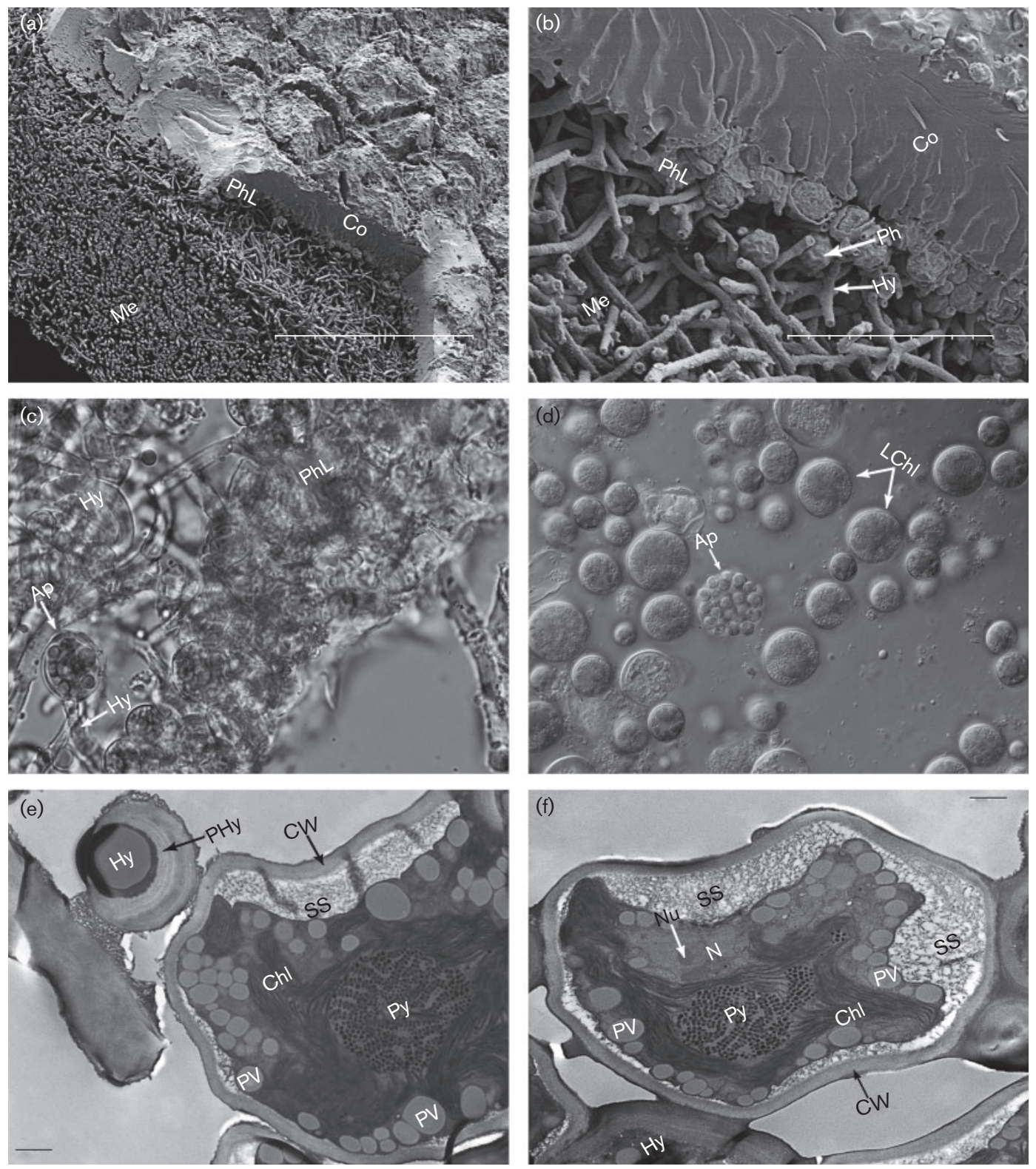

Fig. 2. Ultrasculpture architecture of $C$. convoluta-C. foliacea complex thalli $C 16$ by SEM. (a) Transversal section of the primary thallus with upper cortex (Co), phycobiont layer $(\mathrm{PhL})$ and medulla $(\mathrm{Me})$; bar, $200 \mu \mathrm{m}$. (b) Detail of the phycobiont layer (PhL) showing the interaction between phycobiont $(\mathrm{Ph})$ and hypha (Hy) of the type 'simple' (Honegger, 1986); bar, $40 \mu \mathrm{m}$. (c) Cross section of the thallus by LM (sample C16, fresh). Phycobiont layer ( $\mathrm{PhL}$ ) showing asexual reproduction by aplanospore (Ap). (d) Isolated Asterochloris-type phycobiont showing aplanospore (Ap) and characteristic 'lobed' Asterochloris chloroplast (LChl). Cross section of C16 thallus by TEM (e) and (f) Asterochloris mediterranea sp. nov. phycobiont inside thallus. Bars, $1 \mu \mathrm{m}$. PHy, Peripherial hypha; CW, cell wall; SS, secretory space; Chl, chloroplast; Py, pyrenoid; PV, peripheral vesicles; $\mathrm{N}$, nucleus; $\mathrm{Nu}$, nucleolus.

often branched at their ends, so the chloroplast margin was extended into finger-like, divided lobes (Fig. 4b, c). Rarely, the chloroplast assumed a parietal position, having short, simple lobes. In the late ontogenetic stages, specifically prior to zoo- or aplanosporogenesis, the chloroplast transformed into the parietal type with smooth, never lobed, margins. After a short time, it began to divide into numerous parts in preparation for asexual reproduction (Fig. 4d).

\section{Phycobiont phylogenetic analysis}

At the time of writing, apart from sequences obtained in this study, a total of 19 nrITS phycobiont sequences from $C$. 

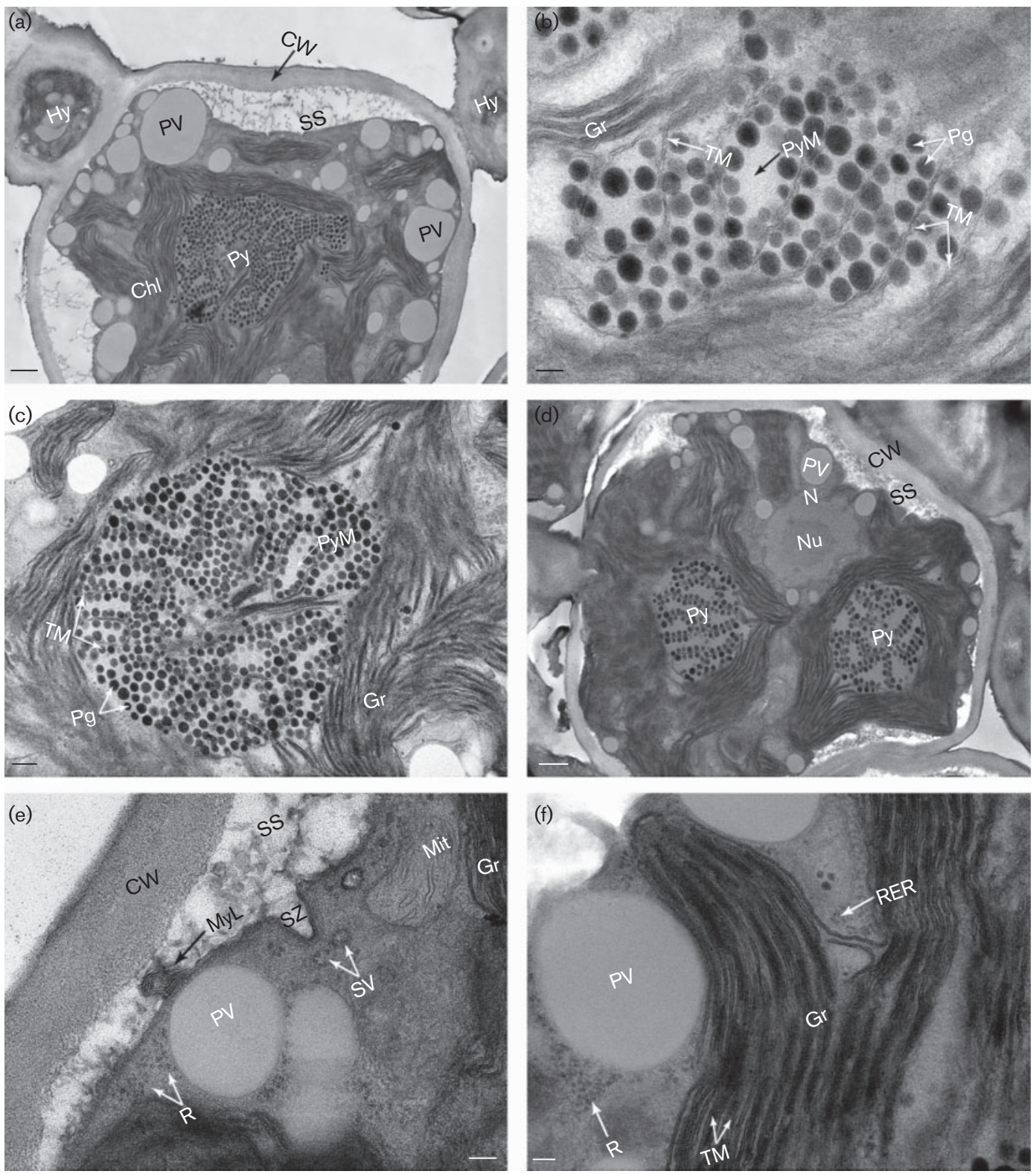

Fig. 3. C. convoluta-C. foliacea complex. Cross section of $\mathrm{C} 16$ thalli by TEM. (a) Asterochloris mediterranea sp. nov. phycobiont inside thallus; bar $1 \mu \mathrm{m}$. (b) and (c) Detail of a pyrenoid (Py), pyrenoglobuli $(\mathrm{Pg})$ associated with the pyrenoid matrix (PyM), grana (Gr) and thylakoid membrane (TM); bars $0.2 \mu \mathrm{m}$ and $0.5 \mu \mathrm{m}$, respectively. (d) Phycobiont showing chloroplasts in duplication phase with two pyrenoids (Py), peripheral vesicles $(P V)$, nucleus $(\mathrm{N})$, nucleolus $(\mathrm{Nu})$, cell wall $(\mathrm{CW})$, secretory space (SS); bar $1 \mu \mathrm{m}$. (e) Detail showing secretory complex: myelin-like bodies (MyL), peripheral vesicles (PV), mitochondria (Mit), ribosome (R), secretory space (SS), secretory vesicle (SV), secretion zone (SZ) and rough endoplasmic reticulum (RER); bar $0.2 \mu \mathrm{m}$. (f) Detail of chloroplast showing peripheral vesicles (PV), ribosome (R), thylakoid membrane (TM), rough endoplasmic reticulum (RER) and grana (Gr). Bar $0.2 \mu \mathrm{m}$

convoluta, C. foliacea, C. rangiformis and C. cervicornis subsp. verticillata were available in GenBank (Piercey-Normore \& DePriest, 2001; Beiggi \& Piercey-Normore, 2007; Bačkor et al., 2010; Pino-Bodas et al., 2010). Only 11 sequences from the C. convoluta-C. foliacea complex, submitted by PinoBodas (Table 2), fitted with those of Asterochloris mediterranea. All of them incorporated information about mycobiont nrITS and substrate. In addition, two sequences
(AF345434 and AF345435) from C. fimbriata and C. rangiformis produced by Piercey-Normore \& DePriest (2001) also fitted with those of $A$. mediterranea, but without any specific information concerning the habitat, location or nrITS sequence of the mycobiont. We included these sequences (Table 2) in the haplotype parsimony networks analysis, but they were excluded from the phycobiont phylogeny analysis due to the lack of actin and LSU rDNA information. 

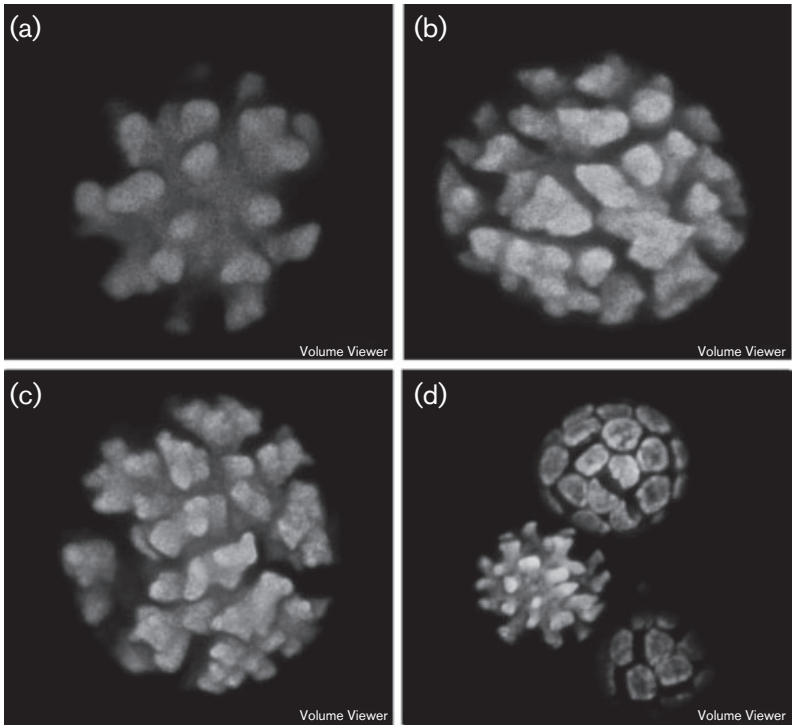

Fig. 4. Confocal microscopy of chloroplast structures in isolated lichen phycobionts ( $A$. mediterranea sp. nov.). (a) A young cell with simple lobes, (b) a mature vegetative cell showing shallowly lobed plastid with simple lobes, (c) a mature vegetative cell with fingerlike divided lobes, (d) two globular aplanosporangia with a large number of aplanospores.

The concatenated Bayesian analysis of the new phycobiont ITS rDNA, actin and LSU rDNA dataset revealed the existence of more than 20 well-resolved lineages within the genus Asterochloris (Fig. 5). The relationships among the lineages correspond well with the phylogeny presented by Škaloud \& Peksa (2010) and Škaloud et al. (2015), including the presence of three moderately to well-supported major clades, A, B and C. The 13 previously described species (A. erici, A. excentrica, A. glomerata, A. irregularis, A. italiana, A. magna, A. phycobiontica, A. echinata, A. friedlii, A. gaertneri, A. leprarii, A. lobophora and A. woessiae) formed well-recognized, distinct lineages. All phycobionts investigated in this study formed a distinct, statistically well-supported lineage, inferred within clade $\mathrm{C}$, in relation to the lineage represented by a single Lepraria phycobiont Nelsen 2585.

Genetic relationships of sequences of A. mediterranea from samples $\mathrm{C} 1$ to $\mathrm{C} 33$ (Table 1) and the sequences selected in Table 2 were analysed by statistical parsimony networks of the ITS rDNA showing minimum differences. All the haplotypes were included in one linked network pointing out a single taxon. Six haplotypes of $A$. mediterranea were found in the $C$. convoluta-C. foliacea complex, and two more haplotypes in the three Cladonia taxa studied here (Fig. 6a). Haplotype 7 (AF345434) and Haplotype 9 (AF345435) were inferred from GenBank. In lichens growing at localities with Miocene gypsum bedrock, only four haplotypes were detected (Fig. $6 \mathrm{~b})$, whereas another four haplotypes appeared randomly in the remaining types of substrates.

\section{ITS2 secondary structure}

A common overall organization of the ITS2 secondary structure could be identified in A. mediterranea (Fig. 7). The ITS2 secondary structure possessed conserved motifs among green algae (Mai \& Coleman, 1997), i.e. four-fingered hand (helix I-IV), a pyrimidine-pyrimidine mismatch in helix II, and a conserved sequence of UGGU on the $5^{\prime}$ side of helix III (Fig. 7). The ITS2 secondary structures were compared first among the A. mediterranea genotypes found in this study to check the occurrence of compensatory base changes (CBCs: nucleotide changes at both sides of paired bases) and hemi-CBCs (changes at only one side of a nucleotide pair, but still preserving pairing) according to Coleman (2003). One insertion, one single base change and one hemi-CBC at positions 18,80 and 88 were identified; these changes were not previously identified by Škaloud \& Peksa (2010).

The ITS2 secondary structure of A. mediterranea was also compared with the previously published structures of Asterochloris lineages 1-16 (Škaloud \& Peksa, 2010). In total, two single base changes at positions 35 and 37, and one hemi-CBC at position 91, were newly identified.

\section{Mycobiont phylogenetic analysis}

To validate the correct lichen identifications, 33 samples were analysed, all of them with the corresponding algal sequences (Table 1). We also included 11 mycobiont sequences selected from those described by Pino-Bodas et al. (2010) in which the phycobiont partner sequences coincided with those of A. mediterranea (Table 2).

The aligned fungal ITS was $481 \mathrm{bp}$ long, including ITS1, 5.8S rDNA and partial ITS2, with 91 variable characters of which 64 were parsimony-informative. We resolved 20 fungal ITS genotypes: 14 in the C. convoluta-C. foliacea complex, three in C. rangiformis and two in $C$ cervicornis s. str. (Fig. 8). BLAST searches produced significant matches with other fungal accessions of species of the genus Cladonia described by Pino-Bodas et al. (2010, 2013a) and Stenroos et al. (2002b). Phylogenetic analysis including mycobiont ITS sequences from Pino-Bodas et al. (2010) selected in this study, showed three well-supported clades corresponding with the C. convoluta-C. foliacea complex, C. rangiformis and C. cervicornis s. str. (Fig. 8) as we previously determined.

\section{DISCUSSION}

The present study contributes to the understanding of the symbiont microalgae of Cladonia lichens providing new insights into the hidden phycobiont diversity found in the genus Asterochloris (Tschermak-Woess, 1980; Bačkor et al., 2010; Škaloud \& Peksa, 2010; Peksa \& Škaloud, 2011; Škaloud et al., 2015). Both morphological and molecular analyses pointed out the presence of a previously unknown taxon described here as Asterochloris mediterranea sp. nov. 


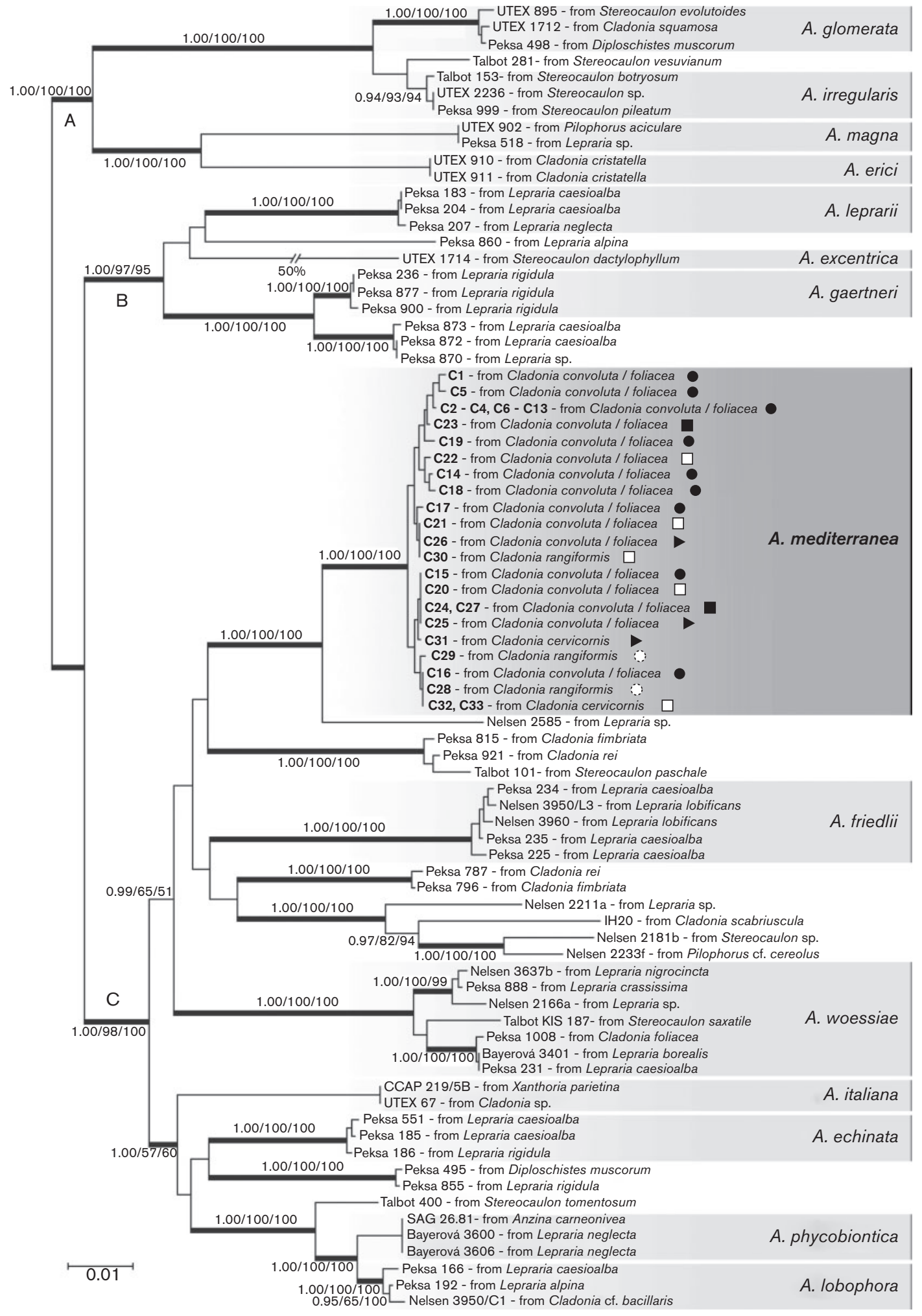

Fig. 5. Unrooted $\mathrm{BI}$ analysis based on the combined ITS rDNA + LSU rDNA + actin dataset using the GTR $+I+\Gamma$ model for ITS rDNA, HKY + I model for LSU rDNA and GTR $+\Gamma$ model for the actin gene. Values at nodes indicate statistical support estimated by three methods - MrBayes posterior node probability (left), ML bootstrap (middle) and MP bootstrap (right). Thick branches represent nodes receiving the highest posterior probability support (1.00). Newly obtained sequences are given in bold type with the type of substrate indicated by symbols: quartzites, siliceous (white square $\square$ ), limestones, calcareous (black square $\mathbf{\square}$ ), sandstones, siliceous (black triangle $\mathbf{D}$ ), Miocene gypsum (black circle $\mathbf{0}$ ) and volcanic (white discontinuous circle 
O). Authentic strains of the genus Asterochloris are marked in grey and the newly defined A. mediterranea is given in bold type.

Strain affiliation to three major clades $(A-C)$ is indicated. Bar, estimated number of substitutions per site.

Barreno, Chiva, Moya et Škaloud linked to the thalli of several members of the genus Cladonia which are widely but not exclusively distributed in Mediterranean and Canarian ecosystems.

This genus was described by Tschermak-Woess (1980) who separated it from the genus Trebouxia on the basis of chloroplast morphology, and later this was supported by more recent confocal and molecular analyses (del Campo et al. 2010a; Peksa \& Škaloud 2008; Škaloud \& Peksa, 2008a, b, 2010; Škaloud et al., 2015). In this work, additional features based on TEM observations and on symbiotic state are proposed for the characterization of species of the genus Asterochloris. The plastid molecular marker LSU rDNA (23S) recommended by del Campo et al. (2010a) was incorporated to build the algal phylogeny, together with the traditionally used nuclear ITS rDNA and actin intron markers (Škaloud \& Peksa, 2010). The correct

(a)

$$
\begin{aligned}
& \text { Cladonia convoluta-Cladonia foliacea complex } \\
& \text { Cladonia rangiformis } \\
& \text { Cladonia cervicomis } \\
& \text { Cladonia fimbriata }
\end{aligned}
$$
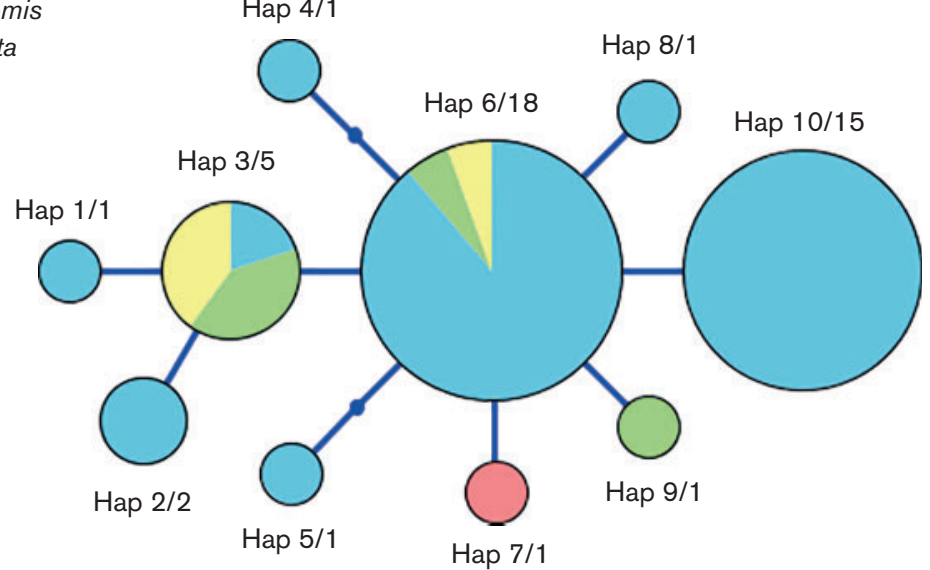

(b)

Miocene gypsum
Granite
Sandstone
Limestone
Volcanic
Quartzite
Unknown

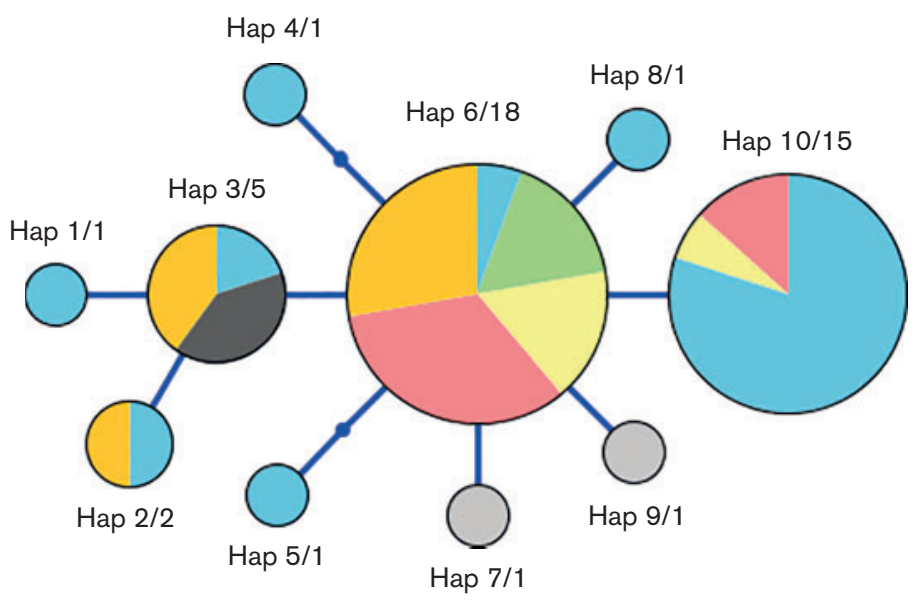

Fig. 6. Statistical parsimony networks obtained for the ITS rDNA A. mediterranea haplotypes found in this study including all available sequences selected from the GenBank database. Size of the circles is proportional to the number of samples sharing that haplotype. Number of samples found sharing that haplotype is given after the haplotype number. Colours in the upper network (a) denote taxa: C. convoluta-C. foliacea complex blue, C. rangiformis green, C. fimbriata pink and C. cervicornis s. str pale yellow. Colours in the lower network (b) denote type of substrate: Miocene gypsum blue, granite green, sandstone pale yellow, limestone pink, volcanic dark grey, quartzite orange, unknown grey. 


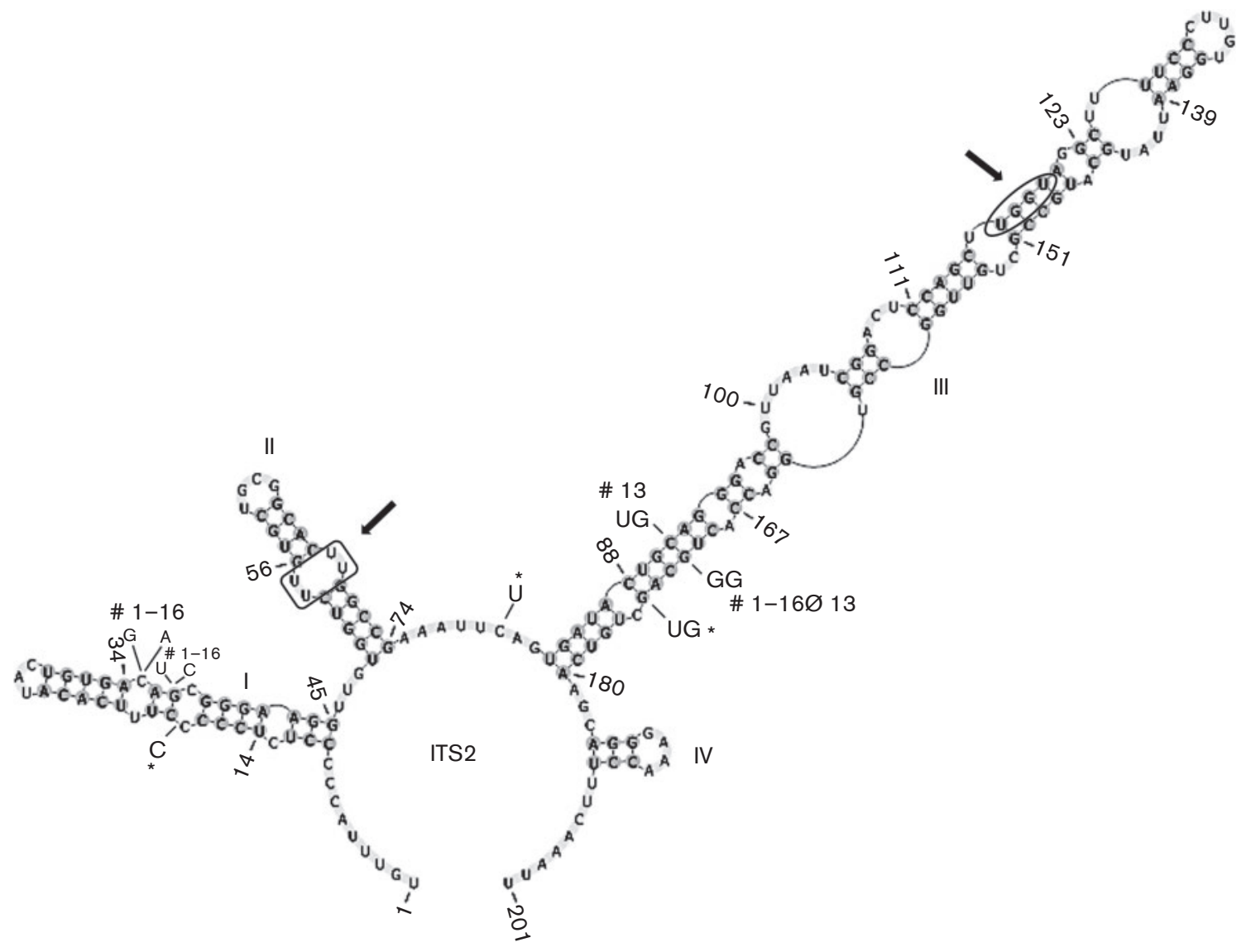

Fig. 7. Predicted secondary structure of the ITS2 transcript of $A$. mediterranea. Base changes between $A$. mediterranea genotypes found in this study are indicated with an asterisk; one single base change, one insertion and one hemi-compensatory base change ( $\mathrm{CBC}$ ). New base changes between $A$. mediterranea and 16 Asterochloris lineages defined by Škaloud \& Peksa (2010) are also indicated; two single base changes and one hemi-CBC. The numbers next to the number sign (\#1-16) specify the Asterochloris clades in which the base changes occurred. The highly conserved U-U in helix II and UGGU motif in helix III (both arrows) are highlighted (Schultz et al., 2005).

identification of the fungal partners was corroborated by the nrITS barcode.

Cellular characteristics in species of the genus Asterochloris have been mostly described from in vitro cultures by $\mathrm{CM}$ and/ or LM techniques. Algae undergo a variety of structural, physiological, and biochemical modifications as a result of lichenization (Galun, 1988; Friedl \& Büdel, 2008); therefore, it seems likewise necessary to know the symbiotic state. TEM ultrastructural observations in symbiosis indicated that in mature cells one large central pyrenoid was always present; sometimes two appeared when the chloroplast was in the duplication phase (Fig. 3d). The pyrenoid ultrastructure fits with the irregularis-type (Fig. 3c) (Friedl, 1989) observed in most species of the genus Asterochloris delimited by Škaloud \& Peksa (2010) (i.e. A. excentrica, A. glomerata, A. irregularis, A. italiana and A. pyriformis).

Škaloud \& Peksa (2008a) proposed that chloroplast morphology could be considered as an important morphological marker for delimitation of species of the genus
Asterochloris under culture conditions. The shallowly lobed plastid with either simple or finger-like lobes, observed in A. mediterranea, also occurred in A. excentrica, $A$. irregularis and A. friedlii (Table S2) (Škaloud \& Peksa, 2008b). Nevertheless, this study has illustrated that CM and TEM techniques should be complementary in the characterization of the chloroplast morphologies (Figs 2e, f and 4) due to the differences in thylakoid arrangements (Fig. 3b, f), as proposed by del Campo et al. (2010b) and Casano et al. (2011) for the taxa Trebouxia TR1 and Trebouxia TR9. The frequent presence of evident nuclei with nucleoli and high amounts of ribosomes could be related to intense metabolic activity of the cells (Boisvert et al., 2007). In addition, the different myelin-like bodies (plasmalemmasomes, lomasomes) in secretory spaces and endoplasmic reticulum highlight the strong cell activity which is required to remove the excess of membranes (Marchant \& Robards, 1968; Robards, 1968). The variable shape of mature cells (spherical to pyriform or kidney-shaped) together with the irregular secretory spaces and the flat and 


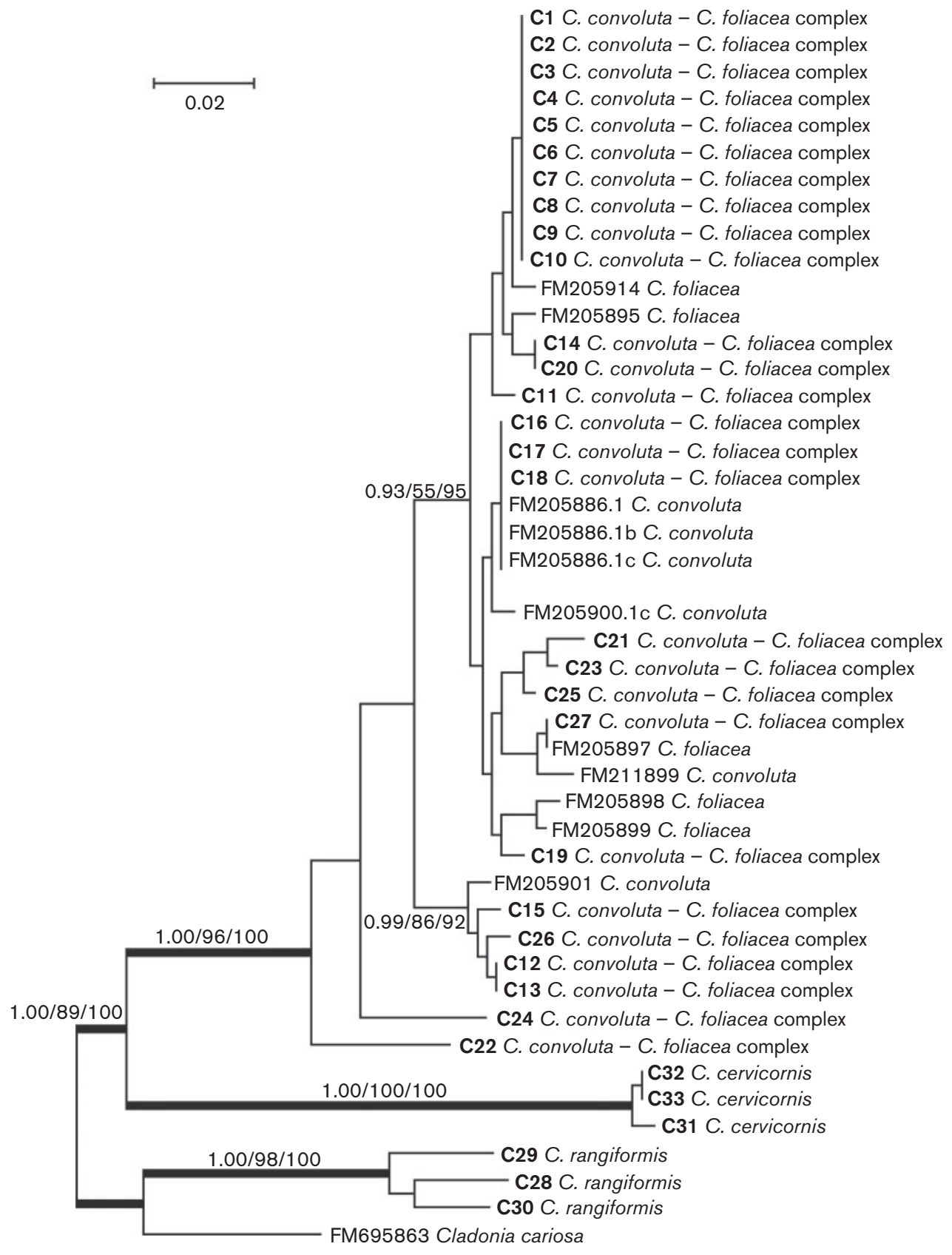

Fig. 8. The $\mathrm{BI}$ analysis of mycobiont ITS rDNA using the GTR $+\Gamma$ model. Values at nodes indicate statistical support estimated by three methods - MrBayes posterior node probability (left), ML bootstrap (middle) and MP bootstrap (right). Thick branches represent nodes receiving the highest posterior probability support (1.00). Newly obtained sequences are given in bold type. Accession numbers of sequences selected from Pino-Bodas et al. (2010) accompany each species name. Bar, estimated number of substitutions per site.

delimited thickening of the cell wall could be useful features to help distinguish species of the genus Asterochloris from those of the genus Trebouxia (data not published).

Species delimitation methods based on single-locus data rely on the assumption that a single gene genealogy is sufficient to illustrate species phylogeny. In Asterochloris algae, evolutionary inferences based on two molecular markers (ITS rDNA and actin sequences) revealed extensive diversity of this algal genus (Škaloud \& Peksa, 2010; Škaloud et al., 2015). In this work, evolutionary inferences based on multiple loci, both nuclear (nrITS and actin) and chloroplastencoded (LSU rRNA), helped us to reinforce the Asterochloris 
phylogeny suggested by Škaloud \& Peksa (2010) and revealed a new well-supported clade (100\% MrBayes/ML/MP) here described as Asterochloris mediterranea sp. nov.

Parsimony networks using our samples $\mathrm{C} 1$ to $\mathrm{C} 33$ and the 13 GenBank sequences showed minimum intraspecific genetic variation among all the haplotypes detected. In addition, we were not able to find any relationship between the haplotype distributions, neither in the types of substrata nor the Cladonia taxa studied here, although Peksa \& Škaloud (2011) demonstrated clear ecological preferences among the majority of Asterochloris lineages.

Putative models of secondary structures have been characterized for the ITS regions of rRNA (Coleman et al., 1998; Joseph et al., 1999; Lalev \& Nazar1998, 1999; Mai \& Coleman, 1997). The maintenance of these structures is important for the proper functioning of the rRNA (Coleman, 2003) and, therefore, ITS rRNA transcripts in Asterochloris have been used as an additional attribute to delimit species boundaries (Beiggi \& PierceyNormore, 2007; Škaloud \& Peksa, 2010; Škaloudová \& Škaloud, 2013). However, it has recently been suggested that differences in the ITS rRNA secondary structures are often not diagnostic at the species level in green algae (Caisová et al., 2011; Škaloud \& Rindi, 2013). Therefore, we would rather consider the presence of nucleotide substitutions in stem regions of the ITS2 rRNA transcript as an attribute of elapsed evolutionary time, indicating that sufficient time has passed to produce a speciation event. Comparing A. mediterranea ITS rRNA secondary structure with the Asterochloris lineages described by Skaloud \& Peksa (2010), low genetic variation was found in ITS rDNA gene regions, which correlates with the absence of CBCs.

In the genus Cladonia, identification of the fungal partners is often problematic and BLAST searches have showed high failure rates (Kelly et al., 2011), thus the DNA barcoding for fungi (nrITS sequences) proposed by Schoch et al. (2012) was used. Even using the barcoding molecular marker, some lichen taxa still remain problematic (PinoBodas et al., 2013a). Several studies have shown that the nrITS region provides a poor resolution for certain species in the genus Cladonia (Fontaine et al., 2010; Kotelko \& PierceyNormore, 2010; Pino-Bodas et al., 2010, 2013b; Steinová et al., 2013). Specifically, C. convoluta (Lam.) Anders and C. foliacea (Huds.) Willd. the currently available data hindered the delimitation of two monophyletic groups (Pino-Bodas et al., 2010). Only three species of the genus Cladonia were separated as independent monophyletic groups, with $C$. convoluta and $C$. foliacea joined together in the same clade, confirming the results found by Pino-Bodas et al. (2010). Although, the case of C. cervicornis complex was clearly solved by Pino-Bodas et al. (2013b).

In summary, the genus Asterochloris is the preferential phycobiont in Cladonia, Lepraria and Stereocaulon lichens, and the diversity of this algal genus needs to be deeply explored in different mycobionts, areas and habitats. The combination of several nuclear and plastid molecular markers as well as ultrastructural (TEM and CM) techniques both in culture and in the symbiotic state should be utilized. Asterochloris mediterranea might exemplify this assertion.

\section{ACKNOWLEDGEMENTS}

Supported by the Ministerio de Economía y Competitividad (MINECO, Spain) (CGL2012-40058-C02-C01), Excellence in Research (Generalitat Valenciana, Spain) (PROMETEOII/2013/021) and Charles University Grant Agency (no. 570313/2013) research project. We want to thank the technicians of the Servicio de Microscopía Electrónica, SCSIE (Universitat de Valencia) who helped us to perform the TEM. Daniel Sheerin revised the manuscript in English.

\section{REFERENCES}

Abràmoff, M. D., Magalhães, P. J. \& Ram, S. J. (2004). Image processing with ImageJ. Biophotonics International 11, 36-43.

Ahmadjian, V. (1987). Coevolution in lichens. Ann N Y Acad Sci 503, 307-315.

Ahmadjian, V. (1993). The Lichen Symbiosis. New York: Wiley.

Ahti, T. (2000). Cladoniaceae. Flora Neotropica Monograph 78, 1-363.

Aschenbrenner, I. A., Cardinale, M., Berg, G. \& Grube, M. (2014). Microbial cargo: do bacteria on symbiotic propagules reinforce the microbiome of lichens? Environ Microbiol 16, 3743-3752.

Bačkor, M., Peksa, O., Škaloud, P. \& Backorová, M. (2010). Photobiont diversity in lichens from metal-rich substrata based on ITS rDNA sequences. Ecotoxicol Environ Saf 73, 603-612.

Barreno, E. (2013). Life is symbiosis. In Once Upon A Time: Lynn Margulis. A Portrait by Colleagues and Friends, pp. 56-60. Edited by Carmen Chica. Septimus, Barcelona. http://www.bubok.es/autores/ carmenchica

Beiggi, S. \& Piercey-Normore, M. D. (2007). Evolution of ITS ribosomal RNA secondary structures in fungal and algal symbionts of selected species of Cladonia sect. Cladonia (Cladoniaceae, Ascomycotina). J Mol Evol 64, 528-542.

Bischoff, H. N. \& Bold, H. C. (1963). Phycological studies IV. Some soil algae from Enchanted Rock and related algal species. University of Texas Publication no. 6318.

Boisvert, F. M., van Koningsbruggen, S., Navascués, J. \& Lamond, A. I. (2007). The multifunctional nucleolus. Nat Rev Mol Cell Biol 8, $574-585$.

Burgaz, A. R. \& Ahti, T. (1992). Contribution to the study of the genera Cladina and Cladonia in Spain. I. Nova Hedwigia 55, 3753.

Burgaz, A. R. \& Ahti, T. (2009). Cladoniaceae (Flora Liquenológica Ibérica vol. 4). Madrid: Sociedad Española de Liquenología.

Caisová, L., Marin, B. \& Melkonian, M. (2011). A close-up view on ITS2 evolution and speciation - a case study in the Ulvophyceae (Chlorophyta, Viridiplantae). BMC Evol Biol 11, 262.

Casano, L. M., del Campo, E. M., García-Breijo, F. J., Reig-Armiñana, J., Gasulla, F., Del Hoyo, A., Guéra, A. \& Barreno, E. (2011). Two Trebouxia algae with different physiological performances are everpresent in lichen thalli of Ramalina farinacea. Coexistence versus competition? Environ Microbiol 13, 806-818.

Castresana, J. (2000). Selection of conserved blocks from multiple alignments for their use in phylogenetic analysis. Mol Biol Evol 17, $540-552$. 
Coleman, A. W. (2003). ITS2 is a double-edged tool for eukaryote evolutionary comparisons. Trends Genet 19, 370-375.

Coleman, A. W., Maria Preparata, R., Mehrotra, B. \& Mai, J. C. (1998). Derivation of the secondary structure of the ITS-1 transcript in Volvocales and its taxonomic correlations. Protist 149, 135-146.

Dal Grande, F., Alors, D., Divakar, P. K., Bálint, M., Crespo, A. \& Schmitt, I. (2014). Insights into intrathalline genetic diversity of the cosmopolitan lichen symbiotic green alga Trebouxia decolorans Ahmadjian using microsatellite markers. Mol Phylogenet Evol 72, $54-60$.

del Campo, E. M., Casano, L. M., Gasulla, F. \& Barreno, E. (2010a). Suitability of chloroplast LSU rDNA and its diverse group I introns for species recognition and phylogenetic analyses of lichen-forming Trebouxia algae. Mol Phylogenet Evol 54, 437-444.

del Campo, E. M., Gimeno, J., Casano, L. M., Gasulla, F., GarcíaBreijo, F., Reig-Armiñana, J., Gasulla, F. \& Barreno, E. (2010b). South European populations of Ramalina farinacea (L.) Ach. share different Trebouxia algae. Bibliotheca Lichenologia 105, 247-256.

del Campo, E. M., Catalá, S., Gimeno, J., del Hoyo, A., MartínezAlberola, F., Casano, L. M., Grube, M. \& Barreno, E. (2013). The genetic structure of the cosmopolitan three-partner lichen Ramalina farinacea evidences the concerted diversification of symbionts. FEMS Microbiol Ecol 83, 310-323.

Fernández-Mendoza, F., Domaschke, S., Garcia, M. A., Jordan, P., Martín, M. P. \& Printzen, C. (2011). Population structure of mycobionts and photobionts of the widespread lichen Cetraria aculeata. Mol Ecol 20, 1208-1232.

Fontaine, K. M., Ahti, T. \& Piercey-Normore, M. D. (2010). Convergent evolution in Cladonia gracilis and allies. Lichenologist 42, 323-338.

Friedl, T. (1989). Comparative ultrastructure of pyrenoids in Trebouxia (Microthamniales, Chlorophyta). Plant Syst Evol 164, $145-159$.

Friedl, T. \& Büdel, B. (2008). Photobionts. In Lichen Biology, pp. 9 26. Edited by T. H. Nash, III. Cambridge: Cambridge University Press.

Galun, M. (1988). Lichenization. In CRC Handbook of Lichenology, vol. II, pp. 153-169. Edited by M. Galun. Boca Raton, FL: CRC Press.

Gardes, M. \& Bruns, T. D. (1993). ITS primers with enhanced specificity for basidiomycetes-application to the identification of mycorrhizae and rusts. Mol Ecol 2, 113-118.

Gasulla, F., de Nova, P. G., Esteban-Carrasco, A., Zapata, J. M., Barreno, E. \& Guéra, A. (2009). Dehydration rate and time of desiccation affect recovery of the lichen alga [corrected] Trebouxia erici: alternative and classical protective mechanisms. Planta 231, 195-208.

Gasulla, F., Jain, R., Barreno, E., Guéra, A., Balbuena, T. S., Thelen, J. J. \& Oliver, M. J. (2013). The response of Asterochloris erici (Ahmadjian) Skaloud et Peksa to desiccation: a proteomic approach. Plant Cell Environ 36, 1363-1378.

Grube, M. \& Hawksworth, D. L. (2007). Trouble with lichen: the reevaluation and re-interpretation of thallus form and fruit body types in the molecular era. Mycol Res 111, 1116-1132.

Hausner, G. \& Wang, X. (2005). Unusual compact rDNA gene arrangements within some members of the Ascomycota: evidence for molecular co-evolution between ITS1 and ITS2. Genome 48, 648660.

Honegger, R. (1986). Ultrastructural studies in lichens. Haustorial types and their frequencies in a range of lichens with trebouxioid photobionts. New Phytol 103, 785-795.
Joseph, N., Krauskopf, E., Vera, M. I. \& Michot, B. (1999). Ribosomal internal transcribed spacer 2 (ITS2) exhibits a common core of secondary structure in vertebrates and yeast. Nucleic Acids Res 27, 4533-4540.

Katoh, K., Misawa, K., Kuma, K. I. \& Miyata, T. (2002). MAFFT: a novel method for rapid multiple sequence alignment based on fast Fourier transform. Nucleic Acids Res 30, 3059-3066.

Kelly, L. J., Hollingsworth, P. M., Coppins, B. J., Ellis, C. J., Harrold, P., Tosh, J. \& Yahr, R. (2011). DNA barcoding of lichenized fungi demonstrates high identification success in a floristic context. New Phytol 191, 288-300.

Koetschan, C., Förster, F., Keller, A., Schleicher, T., Ruderisch, B., Schwarz, R., Müller, T., Wolf, M. \& Schultz, J. (2010). The ITS2 Database III-sequences and structures for phylogeny. Nucleic Acids Res 38 (suppl 1), D275-D279.

Kotelko, R. \& Piercey-Normore, M. D. (2010). Cladonia pyxidata and C. pocillum; genetic evidence to regard them as conspecific. Mycologia 102, 534-545.

Lalev, A. I. \& Nazar, R. N. (1998). Conserved core structure in the internal transcribed spacer 1 of the Schizosaccharomyces pombe precursor ribosomal RNA. J Mol Biol 284, 1341-1351.

Lalev, A. I. \& Nazar, R. N. (1999). Structural equivalence in the transcribed spacers of pre-rRNA transcripts in Schizosaccharomyces pombe. Nucleic Acids Res 27, 3071-3078.

Lechowicz, M. J. \& Adams, M. S. (1974). Ecology of Cladonia lichens. II. Comparative physiological ecology of C. mitis, C. rangiferina, and C. uncialis. Can J Bot 52, 411-422.

Litterski, B. \& Ahti, T. (2004). World distribution of selected European Cladonia species. Symb Bot Upsal 34, 205-236.

Lott, T. J., Burns, B. M., Zancope-Oliveira, R., Elie, C. M. \& Reiss, E. (1998). Sequence analysis of the internal transcribed spacer 2 (ITS2) from yeast species within the genus Candida. Curr Microbiol 36, 6369.

Magain, N. \& Sérusiaux, E. (2014). Do photobiont switch and cephalodia emancipation act as evolutionary drivers in the lichen symbiosis? A case study in the Pannariaceae (Peltigerales). PLoS ONE 9, e89876.

Mai, J. C. \& Coleman, A. W. (1997). The internal transcribed spacer 2 exhibits a common secondary structure in green algae and flowering plants. J Mol Evol 44, 258-271.

Marchant, R. \& Robards, A. W. (1968). Membrane systems associated with the plasmalemma of plant cells. Ann Bot 32, 457-471.

Molins, A., García-Breijo, F. J., Reig-Armiñana, J, del Campo, E. M., Casano, L. M. \& Barreno, E. (2013). Coexistence of different intrathalline symbiotic algae and bacterial biofilms in the foliose Canarian lichen Parmotrema pseudotinctorum. Vieraea: Folia scientarum biologicarum canariensium 41, 349-370.

Muggia, L., Grube, M. \& Tretiach, M. (2008). Genetic diversity and photobiont associations in selected taxa of the Tephromela atra group (Lecanorales, lichenised Ascomycota). Mycol Prog 7, 147160.

Muggia, L., Vancurova, L., Škaloud, P., Peksa, O., Wedin, M. \& Grube, M. (2013). The symbiotic playground of lichen thalli-a highly flexible photobiont association in rock-inhabiting lichens. FEMS Microbiol Ecol 85, 313-323.

Muggia, L., Pérez-Ortega, S., Kopun, T., Zellnig, G. \& Grube, M. (2014). Photobiont selectivity leads to ecological tolerance and evolutionary divergence in a polymorphic complex of lichenized fungi. Ann Bot (Lond) 114, 463-475.

Munger, C. A., Walker, D. A., Maier, H. A. \& Hamilton, T. D. (2008). Spatial analysis of glacial geology, surficial geomorphology, and 
vegetation in the Toolik Lake region: Relevance to past and future land-cover changes. In Ninth International Permafrost Conference, pp. 1255-1260. Edited by D. I. Kane \& K. M Hinkel. Institute of Northern Engineering, University of Alaska Fairbanks, Fairbanks, AK.

Myllys, L., Stenroos, S., Thell, A. \& Ahti, T. (2003). Phylogeny of bipolar Cladonia arbuscula and Cladonia mitis (Lecanorales, Euascomycetes). Mol Phylogenet Evol 27, 58-69.

Nelsen, M. P. \& Gargas, A. (2006). Actin type I introns offer potential for increasing phylogenetic resolution in Asterochloris (Chlorophyta: Trebouxiophyceae). Lichenologist 38, 435-440.

Nelsen, M. P. \& Gargas, A. (2008). Dissociation and horizontal transmission of codispersing lichen symbionts in the genus Lepraria (Lecanorales: Stereocaulaceae). New Phytol 177, 264-275.

Nelsen, M. P. \& Gargas, A. (2009). Symbiont flexibility in Thamnolia vermicularis (Pertusariales: Icmadophilaceae). Bryologist 112, 404 417.

Nyati, S., Scherrer, S., Werth, S. \& Honegger, R. (2014). Green-algal photobiont diversity (Trebouxia spp.) in representatives of Teloschistaceae (Lecanoromycetes, lichen-forming ascomycetes). Lichenologist 46, 189-212.

Nylander, J. A. A. (2004). MrModeltest V2. Distributed by the author. Uppsala: Evolutionary Biology Centre, Uppsala University.

Ohmura, Y., Kawachi, M., Kasai, F., Watanabe, M. M. \& Takeshita, S. (2006). Genetic combinations of symbionts in vegetatively reproducing lichen, Parmotrema tinctorum, based on ITS rDNA sequences. Bryologist 109, 43-59.

Osyczka, P. \& Rola, K. (2013). Phenotypic plasticity of primary thallus in selected Cladonia species (lichenized Ascomycota: Cladoniaceae). Biologia 68, 365-372.

Peksa, O. \& Škaloud, P. (2008). Changes in chloroplast structure in lichenized algae. Symbiosis 46, 153-160.

Peksa, O. \& Škaloud, P. (2011). Do photobionts influence the ecology of lichens? A case study of environmental preferences in symbiotic green alga Asterochloris (Trebouxiophyceae). Mol Ecol 20, 3936-3948.

Piercey-Normore, M. D. (2004). Selection of algal genotypes by three species of lichen fungi in the genus Cladonia. Can J Bot 82, 947-961.

Piercey-Normore, M. D. \& DePriest, P. T. (2001). Algal switching among lichen symbioses. Am J Bot 88, 1490-1498.

Piercey-Normore, M. D., Ahti, T. \& Goward, T. (2010). Phylogenetic and haplotype analyses of four segregates within Cladonia arbuscula s.l. Botany 88, 397-408.

Pino-Bodas, R., Martín, M. P. \& Burgaz, A. R. (2010). Insight into the Cladonia convoluta-C. foliacea (Cladoniaceae, Ascomycota) complex and related species, revealed through morphological, biochemical and phylogenetic analyses. Systematics and Biodiversity 8, 575-586.

Pino-Bodas, R., Burgaz, A. R., Martin, M. P. \& Lumbsch, H. T. (2012a). Species delimitations in the Cladonia cariosa group (Cladoniaceae, Ascomycota). Lichenologist 44, 121-135.

Pino-Bodas, R., Ahti, T., Stenroos, S., Martín, M. P. \& Burgaz, A. R. (2012b). Cladonia conista and C. humilis (Cladoniaceae) are different species. Bibliotheca Lichenologica 108, 161-176.

Pino-Bodas, R., Martín, M. P. \& Burgaz, A. R. (2012c). Cladonia subturgida and C. iberica (Cladoniaceae) form a single, morphologically and chemically polymorphic species. Mycol Prog 11, 269278.

Pino-Bodas, R., Martín, M. P., Burgaz, A. R. \& Lumbsch, H. T. (2013a). Species delimitation in Cladonia (Ascomycota): a challenge to the DNA barcoding philosophy. Mol Ecol Resour 13, 1058-1068.
Pino-Bodas, R., Martín, M. P., Stenroos, S. \& Burgaz, A. R. (2013b). Cladonia verticillata (Cladoniaceae, Ascomycota), new record to Iberian Peninsula. Bot Complut 37, 21-25.

Rambold, G., Friedl, T. \& Beck, A. (1998). Photobionts in lichens: possible indicators of phylogenetic relationships? Bryologist 101, 392397.

Řídká, T., Peksa, O., Rai, H., Upreti, D. K. \& Škaloud, P. (2014). Photobiont diversity in Indian Cladonia Lichens, with special emphasis on the geographical patterns. In Terricolous Lichens in India, pp. 53-71. Edited by H. Rai \& D. K. Upreti. New York: Springer.

Rivas-Martínez, S. \& Rivas-Sáenz, S. (2009). Worldwide bioclimatic classification system. Phytosociological research center. Spain. http:// www.globalbioclimatics.org

Robards, A. W. (1968). On the ultrastructure of differentiating secondary xylem in willow. Protoplasma 65, 449-464.

Ronquist, F., Teslenko, M., van der Mark, P., Ayres, D. L., Darling, A., Höhna, S., Larget, B., Liu, L., Suchard, M. A. \& Huelsenbeck, J. P. (2012). MrBayes 3.2: efficient Bayesian phylogenetic inference and model choice across a large model space. Syst Biol 61, 539-542.

Schoch, C. L., Seifert, K. A., Huhndorf, S., Robert, V., Spouge, J. L., Levesque, C. A., Chen, W., Bolchacova, E., Voigt, K. \& other authors (2012). Nuclear ribosomal internal transcribed spacer (ITS) region as a universal DNA barcode marker for fungi. Proc Natl Acad Sci U S A 109, 6241-6246.

Schultz, J., Maisel, S., Gerlach, D., Müller, T. \& Wolf, M. (2005). A common core of secondary structure of the internal transcribed spacer 2 (ITS2) throughout the Eukaryota. RNA 11, 361-364.

Škaloud, P. \& Peksa, O. (2008a). Comparative study of chloroplast morphology and ontogeny in Asterochloris (Trebouxiophyceae, Chlorophyta). Biologia 63, 873-880.

Škaloud, P. \& Peksa, O. (2008b). Phylogeny, morphology and taxonomic revision of the symbiotic alga Asterochloris (Trebouxiophyceae, Chlorophyta). In Algal Culture Collections 2008, Dunstaffnage Marine Laboratory, UK.

Škaloud, P. \& Peksa, O. (2010). Evolutionary inferences based on ITS rDNA and actin sequences reveal extensive diversity of the common lichen alga Asterochloris (Trebouxiophyceae, Chlorophyta). Mol Phylogenet Evol 54, 36-46.

Škaloud, P. \& Rindi, F. (2013). Ecological differentiation of cryptic species within an asexual protist morphospecies: a case study of filamentous green alga Klebsormidium (Streptophyta). J Eukaryot Microbiol 60, 350-362.

Škaloud, P., Steinová, J., Ridka, T., Vancurova, L. \& Peksa, O. (2015). Assembling the challenging puzzle of algal biodiversity: species delimitation within the genus Asterochloris (Trebouxiophyceae, Chlorophyta). J Phycol accepted 17 Mar 2015.

Škaloudová, M. \& Škaloud, P. (2013). A new species of Chrysosphaerella (Chrysophyceae: Chromulinales), Chrysosphaerella rotundata sp. nov., from Finland. Phytotaxa 130, 34-42.

Spurr, A.R. (1969). A low-viscosity epoxy resin embedding for electron microscopy. J Ultrastruct res 26, 31-43.

Steinová, J., Stenroos, S., Grube, M. \& Škaloud, P. (2013). Genetic diversity and species delimitation of the zeorin-containing red-fruited Cladonia species (lichenized Ascomycota) assessed with ITS rDNA and $\beta$-tubulin data. Lichenologist 45, 665-684.

Stenroos, S. K. \& DePriest, P. T. (1998). SSU rDNA phylogeny of cladoniiform lichens. Am J Bot 85, 1548-1559.

Stenroos, S., Hyvönen, J., Myllys, L., Thell, A. \& Ahti, T. (2002a). Phylogeny of the genus Cladonia s. lat. (Cladoniaceae, Ascomycetes) inferred from molecular, morphological, and chemical data. Cladistics 18, 237-278. 
Stenroos, S., Myllys, L., Thell, A. \& Hyvönen, J. (2002b). Phylogenetic hypotheses: Cladoniaceae, Stereocaulaceae, Baeomycetaceae, and Icmadophilaceae revisited. Mycol Prog 1, 267-282.

Swofford, D. L. (2002). PAUP*. Phylogenetic analysis using parsimony (and other methods), version 4. Sunderland, MA: Sinauer.

Tschermak-Woess, E. (1980). Asterochloris phycobiontica, gen. et spec. nov., der phycobiont der Flechte Varicellaria carneonivea. Plant Syst Evol 135, 279-294.

White, T. J., Bruns, T., Lee, S. J. W. T. \& Taylor, J. W. (1990). Amplification and direct sequencing of fungal ribosomal RNA genes for phylogenetics. In PCR Protocols: A Guide to Methods and Applications, pp. 315-322. Edited by M. A. Innis, D. H. Gelfand, J. J. Sninsky \& T. J. White. New York: Academic Press.

Yahr, R., Vilgalys, R. \& Depriest, P. T. (2004). Strong fungal specificity and selectivity for algal symbionts in Florida scrub Cladonia lichens. Mol Ecol 13, 3367-3378.

Zwickl, D. J. (2006). Genetic algorithm approaches for the phylogenetic analysis of large biological sequence data sets under the maximum likelihood criterion. $\mathrm{PhD}$ dissertation, University of Texas, Austin, TX, USA. 